\title{
Electronically Tunable Current-mode High-order Ladder Low-pass Filters Based on CMOS Technology
}

\author{
Terdsak KUNTO' ${ }^{1}$ Pipat PROMMEE ${ }^{1}$, Muhammad Taher ABUELMA'ATTI ${ }^{2}$ \\ ${ }^{1}$ Department of Telecommunications Engineering, Faculty of Engineering, King Mongkut's Institute of Technology \\ Ladkrabang, Thailand 10520 \\ ${ }^{2}$ King Fahd University of Petroleum and Minerals, Box 203, Dhahran 31261, Saudi Arabia
}

pipat@telecom.kmitl.ac.th

\begin{abstract}
This paper describes the design of current mode low-pass ladder filters based on CMOS technology. The filters are derived from passive RLC ladder filter prototypes using new CMOS lossy and lossless integrators. The all-pole and Elliptic approximations are used in the proposed low-pass filter realizations. The proposed two types of filter can be electronically tuned between $10 \mathrm{kHz}$ and $100 \mathrm{MHz}$ through bias current from $0.03 \mu \mathrm{A}$ to $300 \mu \mathrm{A}$. The proposed filters use $1.5 \mathrm{~V}$ power supply with $3 \mathrm{~mW}$ power consumption at $300 \mu \mathrm{A}$ bias current. The proposed filters are resistorless, use grounded capacitors and are suitable for further integration. The total harmonic distortion (THD) of the low-pass filters is less than $1 \%$ over the operating frequency range. PSPICE simulation results, obtained by using TSMC 0.18um technology, confirm the presented theory.
\end{abstract}

\section{Keywords}

CMOS, current mode, ladder filters, all-pole, elliptic, low-pass filter

\section{Introduction}

Active filters are essential building blocks in analog signal processing particularly in communication, instrumentation and control systems. Over the years, high performance voltage-mode active filters have received much attention. Recently, current-mode filters are becoming more popular with many advantages compared to the voltage-mode counterparts. This is attributed to the simplicity of the current-mode circuit building blocks, the compact design that can be provided and the operation with low supply voltages. Moreover, in current mode the summation and subtraction can be easily realized with relatively simple circuitry. This leads to reduced die area, lower power consumption requirements and improved high frequency performance. On the other hand it is well known that the performance of high-order filters may be preferable than lower-order counterparts in some applications [1]. Thus, using high order filters [2], [3], superior performance can be achieved compared to that obtainable using low-order filters [4], [5]. Moreover, high order filters can save area on the chip. Thus, allowing several subsystems to be integrated on the same chip.

For the design of high-order low-pass active filters, the realization method based on doubly terminated passive RLC ladder prototypes was used [6]. High frequency ladder low-pass filters were presented in [7] by using currentmode integrators. Low input impedance current mirror and grounded capacitors were used for designing differential current-mode integrators. The major drawbacks of the circuits in [7] are the use of excessive number of active and passive components while achieving a relatively narrow tuning range. Current-mode high-order Butterworth lowpass ladder filter using the multiple-output current-controlled current-conveyor (MCCCII) was introduced in [8]. It suffers from the narrow tuning range and the use of large numbers of active devices. All-pole Chebyshev low-pass ladder filters were presented using the fully balanced switched-current integrator [9] and the current-mode damped integrators [10]. However, the proposed circuit in [9] cannot work at high-frequencies and that in [10] suffers from errors in the cut-off frequency. The current-mode filters presented in [11], [12] use simulated RLC ladder networks. The passive components are transformed to coupled-biquad structures that can be realized by multiple output OTAs and grounded capacitors. The realizations of current-mode leapfrog ladder filters using the current-difference buffer-amplifier (CDBA) and the differential-voltage current-conveyor (DVCC) were presented in [13] and [14] respectively. These realizations require many active building blocks and use floating resistors and may, therefore, be not suitable for integration. A different realization method of low-pass leapfrog filters was presented in [15]. The proposed realization uses the second-generation current-conveyor (CCII) and exploits to advantage the frequency-dependence of the differential gain of the operational amplifier (OA) for implementing an integrator. While avoiding the use of externally connected passive components is an advantage, the proposed circuit in [15] lacks electronic tuning of the filter parameters and requires a relatively large number of active devices. In [16] the multiple outputs current conveyor (MOCC) was used to synthesize the low-pass filter (LPF) from the LC ladder prototype. However, the proposed circuit requires a relatively large number of passive components and lacks the 
electronic tunability of the filter parameters. High-order filters using bipolar junction transistor-based DO-CCCII were presented in [17]. Each DO-CCCII uses 20 transistors without including the DC bias current. Since the number of DO-CCCII is equal to the order of the filter +1 , then it is obvious that the proposed circuit requires a large number of bipolar junction transistors. Moreover, because of the dependence on the parasitic resistances at terminals $\mathrm{x}$ of the DO-CCCIIs, the parameters of the circuit are temperature dependent. Another topology for implementing high-order filters using CMOS-based DO-ICCII was introduced in [18]. Each ICCII uses 16 MOSFETs in addition to special bias voltages applied to the gates of two transistors. Of course these bias voltages can be obtained from the DC supply voltages, but this requires additional circuits. Since the number of ICCII equal the order of the required filter +1 , then it is obvious that the area on the chip will be very large. Moreover, the circuit does not enjoy independent control of its parameters. High order voltage mode circuits are also available; see for example [19]. The circuit in [19] suffers from the classical disadvantages of the operation in voltage mode; that is the complicated circuits required for realizing summation and subtraction. Moreover, the circuit uses floating passive elements which is not attractive for integration. Thus, it appears that there is a need for new designs of high-order LPFs enjoying the following attractive features: use of less number of active and passive components, avoid the use of resistors, enjoy the electronic tunability of the filter parameters and are suitable for integration.

Therefore, it is the major intention of this paper to present two transistor level designs of current-mode thirdorder ladder low-pass filters using CMOS technology. The well-known all-pole and Elliptic RLC prototypes are used for synthesizing the circuit elements of the proposed filters. The proposed filters are realized on the transistor-level using lossy integrators, lossless integrators, gain circuits and grounded capacitors. The proposed circuits enjoy the following attractive features: relatively small number of components, low-voltage supply, low-power consumption, no use of externally-connected resistors and wide-range electronic tuning of the filter characteristics. The PSPICE simulation results obtained are in excellent agreement with the theoretical results and confirm that the proposed filters are suitable for high-frequency up to VHF which would be very suitable for designing communications system.

\section{Principle of Operation}

\subsection{CMOS Current-mode Lossy and Lossless Integrators}

The basic lossy integrator, or first order low-pass filter, used in this paper as a main building block is depicted in Fig. 1. With a single input $(X)$ and two outputs $\left(Y_{1}\right.$ and $\left.Y_{2}\right)$ the transfer function of the lossy integrator is described by (1)

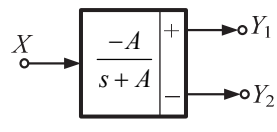

Fig. 1. Lossy integrator block diagram.

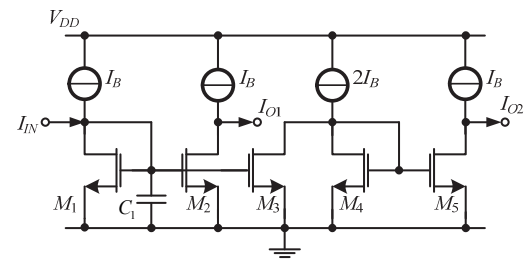

Fig. 2. CMOS-based current-mode lossy integrator.

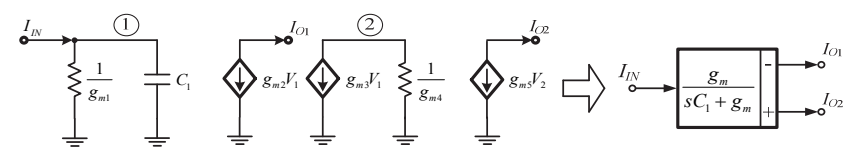

Fig. 3. Small signal model of Fig. 2 and its block diagram $\left(g_{m 1}=g_{m 2}=g_{m 3}=g_{m 4}=g_{m}\right)$.

$$
\frac{Y_{1}}{X}=\frac{-Y_{2}}{X}=\frac{-A}{s+A} .
$$

The current-mode dual output lossy integrator shown in Fig. 1 can be easily implemented on the transistor level by using MOS transistors as shown in Fig. 2. The current transfer functions can be obtained by using the small signal model shown in Fig. 3. Routine analysis of the circuit of Fig. 3 yields the current transfer functions of equations (2) and (3)

$$
\begin{gathered}
\frac{I_{O 1}}{I_{I N}}=\frac{-g_{m 2}}{s C_{1}+g_{m 1}}, \\
\frac{I_{O 2}}{I_{I N}}=\frac{g_{m 3} g_{m 5} / g_{m 4}}{s C_{1}+g_{m 1}}
\end{gathered}
$$

where $g_{m i}$ is transconductance of transistor $i$. Assume that transistor $M_{1}-M_{4}$ are matched $\left(g_{m 1}=g_{m 2}=g_{m 3}=g_{m 4}=g_{m}\right)$, the current transfer functions of Fig. 3 become

$$
\begin{aligned}
& \frac{I_{O 1}}{I_{I N}}=\frac{-g_{m}}{s C_{1}+g_{m}}, \\
& \frac{I_{O 2}}{I_{I N}}=\frac{g_{m}}{s C_{1}+g_{m}} .
\end{aligned}
$$

On the other hand, the lossless integrator can be easily realized by modifying the lossy integrator as follows. First, an inverting gain is added to the output of inverting lossy integrator [20]. Second, the inverted output is fed back to the input as shown in Fig. 4. Thus, the non-inverting and inverting current-mode lossless integrator transfer functions obtained at ports $Z_{1}$ and $Z_{2}$, respectively, can be expressed as

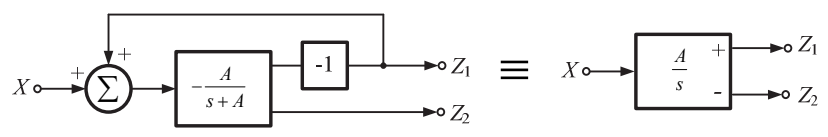

Fig. 4. Lossless integrator block diagram. 


$$
\frac{Z_{1}}{X}=\frac{-Z_{2}}{X}=\frac{A}{S}
$$

Figure 5 shows a possible transistor level realization for the lossless integrator shown in the block diagram of Fig. 4. The output of the lossy integrator formed of transistors $\mathrm{M}_{1}, \mathrm{M}_{2}$ and $\mathrm{M}_{3}$ is connected to the inverting gain unit formed of transistors $\mathrm{M}_{4}$ and $\mathrm{M}_{5}$ and then fed back to the input. There are two current outputs $I_{O B}$ (port $Z_{+}$) and $I_{O A}$ (port $Z_{\text {-) }}$ taken from transistors $\mathrm{M}_{6}$ and $\mathrm{M}_{2}$, respectively.

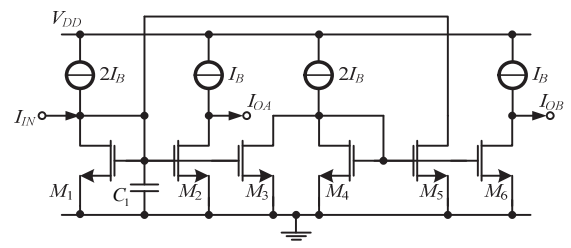

Fig. 5. CMOS-based current-mode lossless integrator.

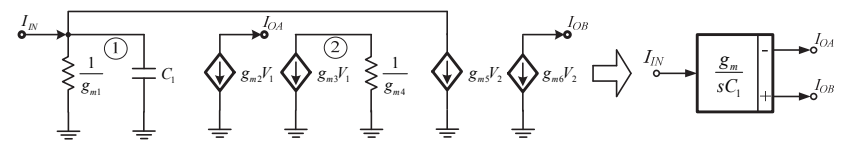

Fig. 6. Small signal model of Fig. 5 and its block diagram $\left(g_{m 1}=g_{m 2}=g_{m 3}=g_{m 4}=g_{m 5}=g_{m 6}=g_{m}\right)$

Assuming that transistors $M_{1}-M_{6}$ are matched with $g_{m 1}=g_{m 2}=g_{m 3}=g_{m 4}=g_{m 5}=g_{m 6}=g_{m}$, the current transfer functions can be obtained by using the small signal model shown in Fig. 6. Routine analysis of the small signal model of Fig. 6 yields the following transfer functions

$$
\begin{aligned}
& \frac{I_{O A}}{I_{I N}}=\frac{-g_{m}}{s C_{1}}, \\
& \frac{I_{O B}}{I_{I N}}=\frac{g_{m}}{s C_{1}} .
\end{aligned}
$$

From Fig. 3 and Fig. 6, the input impedance of both integrators can be expressed as

$$
Z_{i n}=\frac{1}{g_{m}+s C_{1}} .
$$

In equations (2)-(5) and (7)-(8) the transconductance $g_{m}$ of any transistor is given by

$$
g_{m}=\frac{\partial I_{D}}{\partial V_{G S}} \approx \sqrt{2 \mu C_{O X}(W / L) I_{D}}
$$

where $\mu, C_{o x}, W$ and $L$ are surface mobility, channel oxide capacitance, channel width and channel length of the MOS transistor, respectively and $I_{D}$ is the bias current $I_{B}$ of the transistor. Equation (10) clearly shows that transconductance can be tuned by adjusting the bias current $I_{B}$. Thus, the parameters of the lossy and lossless integrators of Figs. 2 and 5 can be electronically tuned.

\subsection{Synthesis of RLC Ladder Low-Pass Filters}

This section describes the synthesis procedure of ladder filter based on the signal flow graph (SFG) method.
Two types of passive RLC ladder low-pass filter; the allpole and Elliptic filters [21-25], are provided as prototypes. In some applications, a higher fall off rate is required in the transition band; that is a very high attenuation is required very near the cutoff frequency. This requirement mandates the use of elliptic functions in the approximation of the filter transfer function and leads to the design of Elliptic or Cauer filters [22]

Firstly, the doubly terminated current-mode thirdorder all-pole passive RLC ladder low-pass filter prototype shown in Fig. 7 is considered.

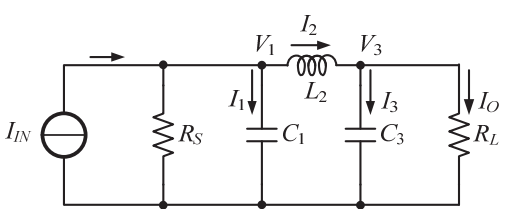

Fig. 7. Current-mode third-order all-pole low-pass RLC ladder prototype.

Considering the prototype shown in Fig. 7, using KCL the current and voltage relationship can be written as

$$
\begin{gathered}
I_{1}=I_{I N}-\frac{V_{1}}{R_{S}}-I_{2}, \\
V_{1}=\frac{I_{1}}{s C_{1}}, \\
V_{2}=V_{1}-V_{3}, \\
I_{2}=\frac{V_{2}}{s L_{2}}, \\
V_{3}=\frac{I_{3}}{s C_{3}}, \\
I_{3}=I_{2}-\frac{V_{3}}{R_{L}} .
\end{gathered}
$$

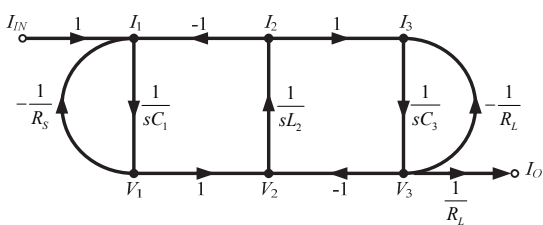

(a)

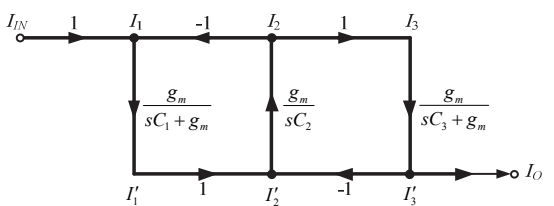

(b)

Fig. 8. (a) SFG of third-order all-pole low-pass ladder filter in Fig. 7, (b) Completed current-mode SFG of Fig. 8(a).

Using equations (11)-(16), a SFG can be constructed and is shown in Fig. 8(a). Voltages at different nodes and currents in different branches are forming the nodes of the SFG. The voltage nodes need to be transformed into current nodes. The transconductance $g_{m}$ is used to normalize 
the voltage nodes to current nodes. The variables $R_{S}=R_{L}$ $=1 / g_{m}$ are used to simplify the realization method. Furthermore, lossless integrators with its negative feedback in lefthand and right-hand sides can be replaced by lossy integrators. The finalized current-mode SFG is shown in Fig. 8(b). It can be seen that the all-pole low-pass ladder filter can be designed based on lossy and lossless integrators.

Secondly, the passive RLC doubly terminated thirdorder Elliptic low-pass filter shown in Fig. 9 is also used as a prototype.

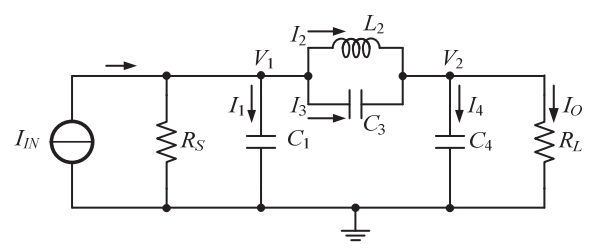

Fig. 9. Prototype current-mode third-order Elliptic low-pass RLC ladder filter.

Considering the prototype in Fig. 9, routine analysis yields the following current and voltage relationships:

$$
\begin{gathered}
I_{1}=I_{I N}-\frac{V_{1}}{R_{S}}-I_{2}-I_{3}, \\
I_{3}=\left(V_{1}-V_{2}\right) s C_{3}, \\
V_{1}=\frac{I_{1}}{s C_{1}}, \\
V_{1}=\frac{I_{I N}-I_{2}-V_{1} / R_{S}}{s\left(C_{1}+C_{3}\right)}+V_{2} \frac{C_{3}}{C_{1}+C_{3}}, \\
I_{4}=I_{2}+I_{3}-I_{O}, \\
V_{2}=\frac{I_{4}}{s C_{4}}, \\
V_{2}=\frac{I_{2}-I_{O}}{s\left(C_{3}+C_{4}\right)}+V_{1} \frac{C_{3}}{C_{3}+C_{4}} .
\end{gathered}
$$

Using (17)-(23), a modified RLC prototype can be redrawn as shown in Fig. 10. For simplicity, the current terms $\left(I_{I N}-I_{2}-V_{1} / R_{S}\right)$ and $\left(I_{2}-I_{O}\right)$ in (20) and (23) are replaced by $I_{x}$ and $I_{y}$ respectively and the capacitor $C_{3}$ is replaced by two new capacitors $\left(C_{1}+C_{3}\right)$ and $\left(C_{3}+C_{4}\right)$ connected with two dependent sources as shown in Fig. 10.

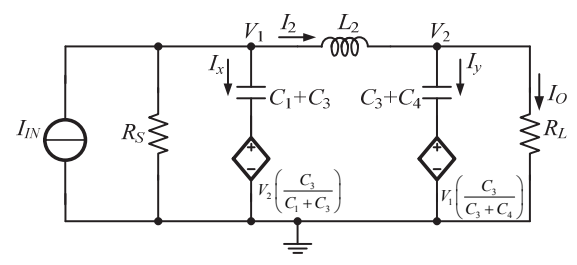

Fig. 10. Modified current-mode third-order Elliptic low-pass RLC ladder filter.

From equations (17)-(23) and Fig. 10, a SFG can be drawn as shown in Fig. 11(a). Voltages at different nodes and currents in different branches are forming the nodes of voltage and current in the SFG. The voltage nodes need to be transformed into current nodes. The transconductance $g_{m}$ is used to normalize the voltage nodes to current nodes. The variables $R_{S}=R_{L}=1 / g_{m}$ are used to simplify the realization method. Furthermore, lossless integrators with its negative feedback in left-hand and right-hand sides can be replaced by lossy integrators. The finalized current-mode SFG is shown in Fig. 11(b). It can be seen that the elliptic low-pass ladder filter can be designed based on lossy, lossless integrators and current gains.

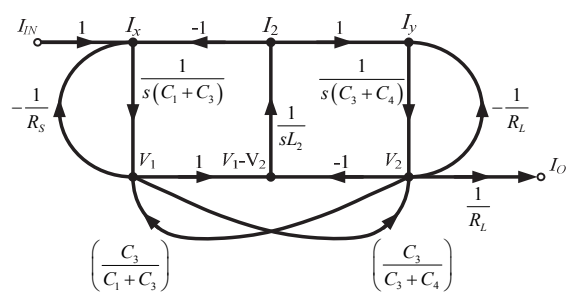

(a)

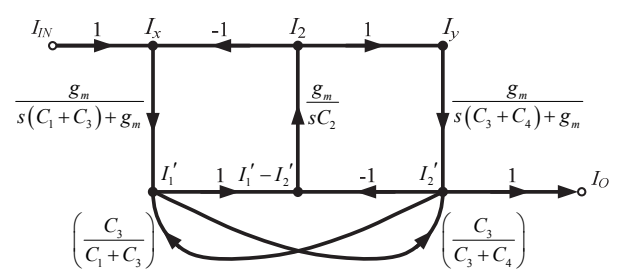

(b)

Fig. 11. (a) SFG of third-order elliptic low-pass ladder filter in Fig. 10, (b) Completed current-mode SFG of Fig. 11(a)

\section{CMOS Realization of Ladder Low- Pass Filters}

Considering the SFG shown in Fig. 8(b), the third-order all-pole low-pass ladder filter can be constructed by using 2 lossy integrators and a lossless integrator. In current-mode realizations, summing and subtracting can be easily implemented by direct connection without additional circuit elements. Using the block diagrams shown in Figs. 3 and 6 and the SFG in Fig. 8(b), a third-order allpole ladder low-pass filter can be realized as shown in the block diagram of Fig. 12.

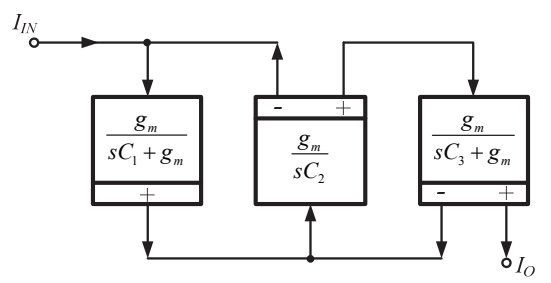

Fig. 12. Third-order Chebyshev low-pass ladder filter.

Using the block diagram in Fig. 12 and the circuits shown in Figs. 2 and 5, the complete circuit diagram of the synthesized third-order all-pole ladder low-pass filter is shown in Fig. 13. In Fig. 13, the bias currents are realized by using PMOS current mirrors $M_{B i}$ with identical aspect ratios for providing the equal bias currents. 
In a similar way using the Elliptic filter SFG shown in Fig. 11(b), the third-order Elliptic low-pass ladder filter can be constructed by using lossy, lossless integrators and additional current gains. Inspection of Fig. 11(b) shows that the SFG of Elliptic filter has two feedback paths. The current gains are needed to provide the feedback paths. Elliptic third-order ladder low-pass filter can be implemented by using the block diagrams of two lossy integrators and a lossless integrator. Two multiple outputs $(+,-, k)$ current splitters are used to provide the current feedback between $I_{1}{ }_{1}$ and $I_{2}{ }_{2}$. It can be seen that the proposed circuit requires only three capacitors while the prototype RLC filter uses three capacitors and one inductor. The current-gain can be easily realized by defining the aspect ratios of the particular transistors and its bias current. Using the SFG in Fig. 11(b), the design of third-order elliptic low-pass ladder filter can be realized by using the block diagram of two lossy integrators, one lossless integrator and two current splitters as shown in Fig. 14.
Using the block diagram in Fig. 14 and the circuits shown in Figs. 2 and 5, the complete circuit of the thirdorder Elliptic low-pass ladder filter is shown in Fig. 15. It can be seen that the proposed circuit requires only three capacitors while the prototype RLC filter of Fig. 9 requires three capacitors and one inductor. In Fig. 15 the bias currents are implemented using PMOS current mirrors $M_{B i}$ with identical aspect ratios for providing the equal bias currents. As shown in the block diagram in Fig. 14, two extra current amplifiers with current gain $k$ are required. In Fig. 15 these current amplifiers are realized by using the MOSFET transistors shown in the two dotted boxes. Note that the capacitors used in the circuits are on-chip type [26] as shown in Fig. 16. These capacitors can be simultaneously implemented with the whole circuit on the chip for full integration. This would also enable high frequency operation as it reduces the parasitic capacitances associated with of-the-chip connections.

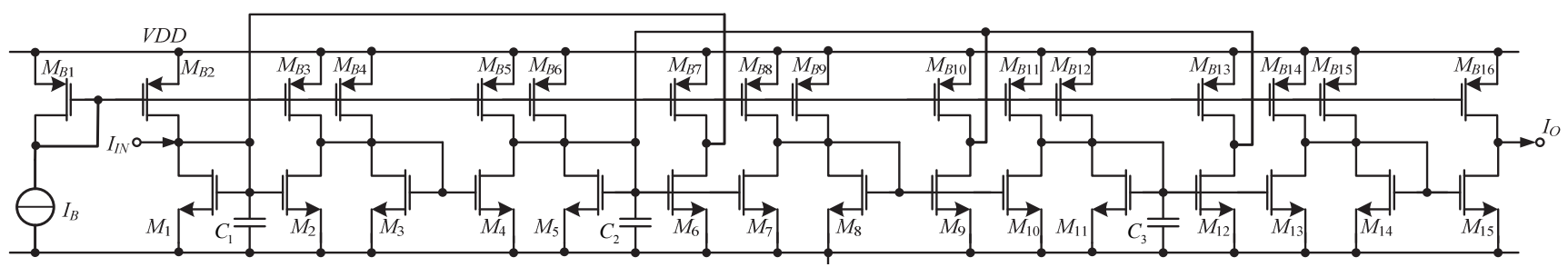

Fig. 13. CMOS current-mode tunable $3^{\text {rd }}$ order all-pole low-pass ladder filter.

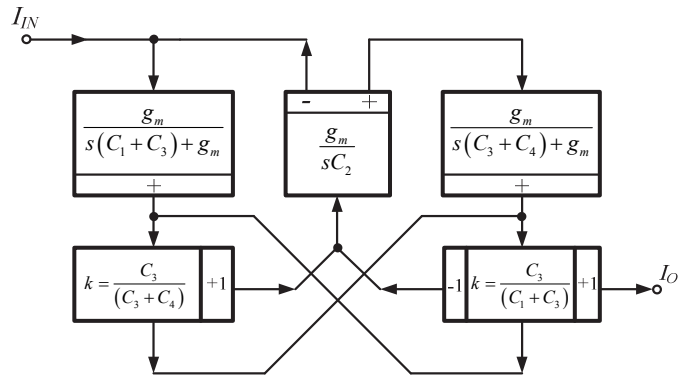

Fig. 14. Third-order Elliptic low-pass ladder filter.

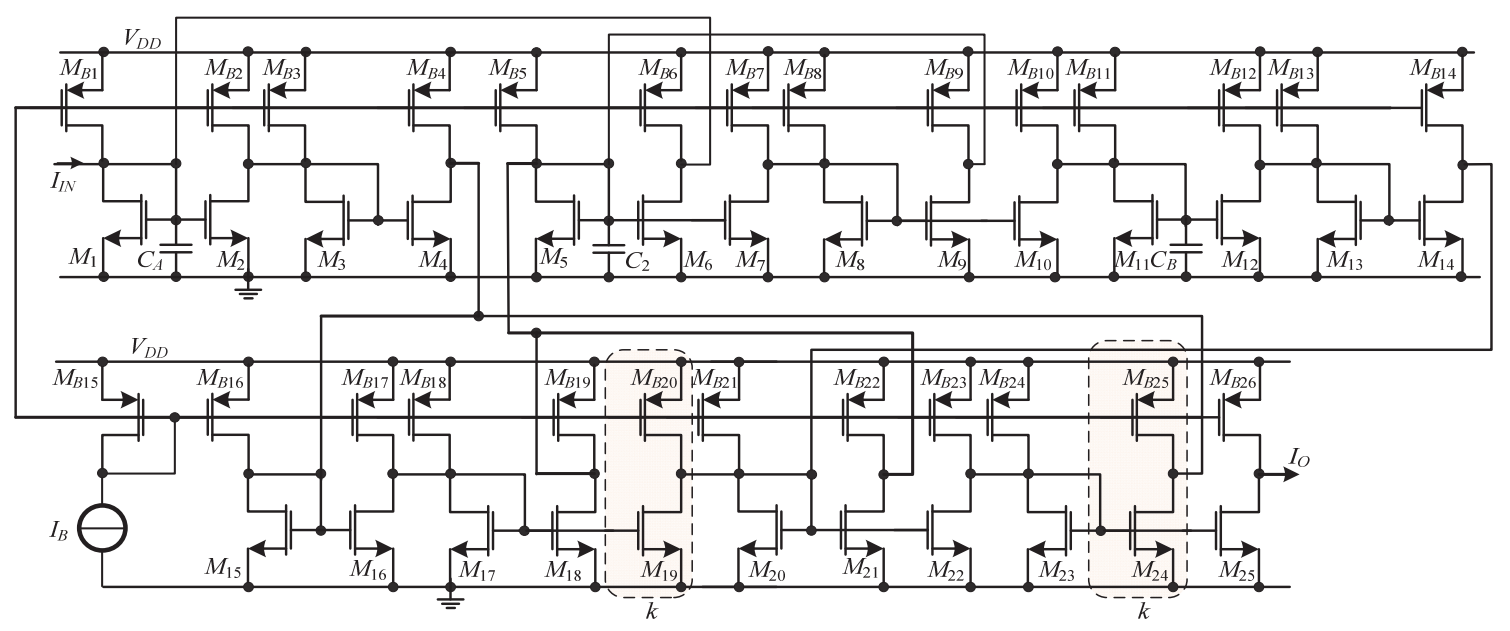

Fig. 15. CMOS current-mode tunable ladder elliptic low-pass filter. 


\section{Effect of Non-idealities}

This section shows the influence of the NMOS transistors parasitic elements. Lossy and lossless integrators are the main building blocks of the proposed filters. Therefore, due to the transistor parasitic elements, when the circuits work at relatively high-frequencies their performances may deviate from the theory. Non-ideal analysis of integrators can be performed by using the small signal model of NMOS in Fig. 16.

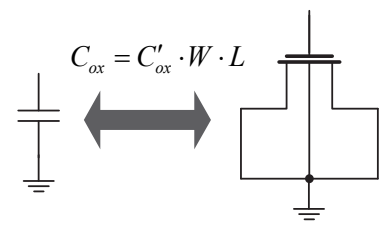

Fig. 16. NMOS capacitor used for the grounded capacitors.

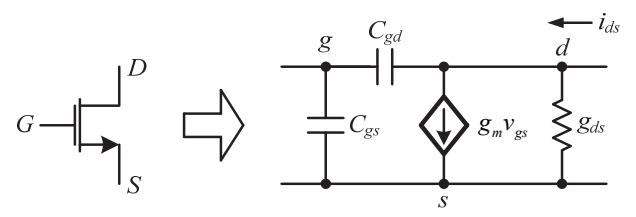

Fig. 17. Small signal model of MOS transistor.

In the small signal model shown in Fig. 17, the input parasitic capacitances $C_{g s}$ and $C_{g d}$, the conductance $g_{d s}$ and the transconductance $g_{m}$ are incorporated. The effects of the transistor parasitic components on the performance of the proposed low-pass filters are described in the following subsections.

\subsection{Parasitic Capacitances}

This section will consider the effect of the parasitic capacitances $C_{g d}$ and $C_{g s}$, which is important for determining the performance of a CMOS circuit, particularly at high frequencies.

\subsubsection{Lossy Integrators}

Using the small signal model of MOS transistor of Fig. 17, considering only the parasitic gate-drain capacitance $C_{g d}$, that affects the inverting and non-inverting lossy integrator, and assuming that the transconductances of MOS transistors are matched, then transfer functions of the lossy integrator of Fig. 2 can be approximated by (24) and (25), respectively

$$
\begin{gathered}
\frac{I_{O 1}}{I_{I N}}=\frac{-g_{m}}{g_{m}+s\left(C_{g d 2}+C_{1}\right)}, \\
\frac{I_{O 2}}{I_{I N}}=\frac{g_{m}}{g_{m}+s\left(3 C_{g d 2}+C_{g d 4}+C_{1}\right)} .
\end{gathered}
$$

Similarly, considering the parasitic gate-source capacitance $C_{g s}$ that affects inverting and non-inverting lossy integrator, and assuming that the transconductances of MOS transistors are matched, then the transfer functions of the lossy integrators are given by (26) and (27), respectively

$$
\begin{gathered}
\frac{I_{O 1}}{I_{I N}}=\frac{-g_{m}}{g_{m}+s\left(C_{g s 1}+C_{g s 2}+C_{1}\right)}, \\
\frac{I_{O 2}}{I_{I N}}=\frac{g_{m}}{g_{m}+s\left(C_{g s 3}+C_{g s 4}+C_{g s 1}+C_{g s 2}+C_{1}\right)} .
\end{gathered}
$$

Equations (23)-(26) show the effect of the parasitic capacitances on the performance of the lossy integrator. In saturation operation, the parasitic gate to drain capacitance $C_{g d}$ and gate to source capacitance $C_{g s}$ will vary anywhere within the ranges depending on the bias conditions involved [22]. For the specific case where it is assumed that the parasitic capacitances $C_{g d i}=C_{g d}, C_{g s i}=C_{g s}$ with $C_{g d}=$ $W L_{D} C_{o x}$ and $\left.C_{g s}=W\left((2 / 3)(L)+L_{D}\right)\right) C_{o x}$, it can be seen that parasitic capacitances $C_{g d}$ and $C_{g s}$ produce a small deviation in the frequency response of the low-pass filter. To prevent significant errors, the capacitance $C_{1}$ should be

$$
C_{1}>4\left(C_{g s}+C_{g d}\right) .
$$

\subsubsection{Lossless Integrators}

In a similar way, the effect of the parasitic gate-drain and gate-source capacitances $C_{g d}$ and $C_{g s}$, that affect the inverting and non-inverting lossless integrator of Fig. 5 can be considered. Assuming that the transconductances of MOS transistors are matched, the transfer functions of the lossless integrators affected by the parasitic capacitances $C_{g d}$ and $C_{g s}$ can be expressed as

$$
\begin{gathered}
\frac{I_{O A}}{I_{I N}}=\frac{-g_{m}}{s\left(4 C_{g d 3}+4 C_{g d 5}+C_{g d 2}+C_{1}\right)}, \\
\frac{I_{O B}}{I_{I N}}=\frac{g_{m}}{s\left(4 C_{g d 2}+4 C_{g d 4}+C_{g d 5}+C_{1}\right)}, \\
\frac{I_{O A}}{I_{I N}}=\frac{-g_{m}}{s\left(C_{g s 1}+C_{g s 2}+C_{g s 3}+C_{g s 4}+C_{g s 5}+C_{1}\right)}, \\
\frac{I_{O B}}{I_{I N}}=\frac{g_{m}}{s\left(C_{g s 1}+C_{g s 2}+C_{g s 3}+C_{g s 4}+C_{g s 5}+C_{1}\right)} .
\end{gathered}
$$

Inspection of equations (29)-(32), shows the effect of the parasitic capacitances $C_{g d}$ and $C_{g s}$ on the performance of the lossless integrator. In saturation region, the parasitic gate to drain and source capacitances $C_{g d}$ and $C_{g s}$ will vary anywhere within the ranges depending on the bias conditions involved. To prevent significant errors, the selected capacitance $C_{1}$ should be

$$
C_{1}>>9 C_{g d}+5 C_{g s} .
$$

From (33), it is clear that the errors can be minimized by selecting relatively large values for the capacitance $C_{1}$.

\subsection{Parasitic Resistance $r_{d s}$}

The most commonly used small-signal model for a MOS transistor operating in the active region is shown in Fig. 17. The voltage-controlled current source $g_{m} v_{g s}$ is the most important component of the model, with the transistor current-voltage relationship given by 


$$
i_{D S}=\frac{\mu_{n} C_{o x} W}{2 L}\left(v_{G S}-V_{T}\right)^{2}\left(1+\lambda v_{D S}\right)
$$

where $\lambda$ represents the channel-length modulation effect which is normally less than 1 . It produces the slope of drain current as a function of the voltage $v_{D S}$. The channel conductance will be dependent upon $L$ through $\lambda$ which is inversely proportional to $L(\lambda \propto 1 / L)$. The small-signal channel conductance $g_{d s}$ is expressed as

$$
\frac{1}{r_{d s}}=g_{d s}=\frac{\partial i_{D S}}{\partial v_{D S}}=\frac{\lambda i_{D S}}{1+\lambda v_{D S}} \approx \lambda i_{D S} .
$$

Equation (35) shows the direct effect of the drain current (bias current) and the channel-length modulation $\lambda$ on $g_{d s}$. This would affect the gain and the cut-off frequency of the filter. It is a trade-off situation especially if short-channel $(L<5 \mu \mathrm{m})$ is used in order to minimize the die area of the chip and its power consumption. However, the resulting small reduction in gain of the filters may be tolerated and can be easily compensated in the succeeding stages.

\subsubsection{Lossy Integrators}

Using the small signal model of MOS transistor with parasitic conductance and assuming that the transconductances of the MOS transistors are matched, where it is assumed that $g_{m i}=g_{m}$ and $g_{d s i}=g_{d s}$ the transfer functions of the lossy integrators can be approximated by

$$
\begin{aligned}
& \frac{I_{O 1}}{I_{I N}} \approx-\left(\frac{g_{m}+g_{d s}}{g_{m}+2 g_{d s}}\right) \frac{g_{m}\left(g_{m}+2 g_{d s}\right) / C_{1}\left(g_{m}+g_{d s}\right)}{s+g_{m}\left(g_{m}+2 g_{d s}\right) / C_{1}\left(g_{m}+g_{d s}\right)}, \\
& \frac{I_{O 2}}{I_{I N}} \approx\left(\frac{g_{m}}{3 g_{d s}+g_{m}}\right) \frac{g_{m}\left(g_{m}+3 g_{d s}\right) / C_{1}\left(g_{m}+2 g_{d s}\right)}{s+g_{m}\left(g_{m}+3 g_{d s}\right) / C_{1}\left(g_{m}+2 g_{d s}\right)},
\end{aligned}
$$

Inspection of equation (36) and (37) clearly shows that magnitude and the cut-off frequency of the lossy integrators will be slightly affected by $g_{d s}$. In order to avoid significant errors in the transfer functions of the lossy integrators the transistor transconductance $g_{m}$ must satisfy the condition

$$
g_{m}>3 g_{d s} .
$$

Inspection of equations (10) and (38) shows that significant errors can be avoided if large transistor width $W$ is used.

\subsubsection{Lossless Integrators}

In a similar way, taking into consideration the effect of the parasitic drain-source conductance $g_{d s}$, the transfer functions of the inverting and non-inverting lossless integrators can be expressed as

$$
\begin{aligned}
& \frac{I_{O A}}{I_{I N}}=\frac{-\left(g_{m}\right)^{2}}{g_{m}\left(g_{d s 1}+g_{d s 3}+g_{d s 4}+g_{d s 5}\right)+s C_{1}\left(g_{m}+g_{d s 3}+g_{d s 4}\right)}, \\
& \frac{I_{O B}}{I_{I N}}=\frac{\left(g_{m}\right)^{2}}{g_{m}\left(g_{d s 1}+g_{d s 2}+g_{d s 3}+g_{d s 4}\right)+s C_{1}\left(g_{m}+g_{d s 2}+g_{d s 3}\right)} .
\end{aligned}
$$

Equations (39) and (40) show how the parasitic drain to source conductance $g_{d s}$ affects the transfer functions of the lossless integrator. Assuming that the transconductances of MOS transistors are matched equations (39) and (40) reduce to

$$
\begin{aligned}
& \frac{I_{O A}}{I_{I N}} \approx \frac{-g_{m}}{4 g_{d s}+s C_{1}}=\left(\frac{-g_{m}}{4 g_{d s}}\right) \frac{4 g_{d s} / C_{1}}{s+4 g_{d s} / C_{1}}, \\
& \frac{I_{O B}}{I_{I N}} \approx \frac{g_{m}}{4 g_{d s}+s C_{1}}=\left(\frac{g_{m}}{4 g_{d s}}\right) \frac{4 g_{d s} / C_{1}}{s+4 g_{d s} / C_{1}} .
\end{aligned}
$$

From equations (41) and (42), it can be seen that both types of lossless integrator are affected by the parasitic conductance $g_{d s}$ as a parasitic pole at low frequency $\omega_{L}=4 g_{d s} / C_{1}$ will appear in each transfer function. However, these effects will be significant at very low-frequency where the working frequency is much less than the frequency of the parasitic pole. Thus, the resulting parasitic poles will provide the lower frequency limitation of lossless integrators and the maximum gain at low frequency $|k|=g_{m} / 4 g_{d s}$.

\subsection{Transistor Mismatches}

This section will consider the effect of transistor mismatches on the performance of the proposed integrator circuits.

\subsubsection{Lossy Integrators}

Consider the lossy integrator circuit of Fig. 2. Using the small signal model of the MOS transistor of Fig. 17, ignoring the effects of $C_{g s}$ and $g_{d s}$ and assuming that the transconductances of the MOS transistors are $g_{m 1}$ and $g_{m 2}$ for the transistors $M_{1}$ and $M_{2}$ respectively, reanalysis shows that the transfer function of the lossy integrator of Fig. 2 can be expressed by (43)

$$
\frac{I_{O 1}}{I_{I N}}=\frac{-I_{O 2}}{I_{I N}}=\left(\frac{-g_{m 2}}{g_{m 1}}\right)\left(\frac{g_{m 1}}{g_{m 1}+s C_{1}}\right) .
$$

Inspection of equation (43) shows that, due to the transistor mismatch, the low frequency gain of the lossy integrator will deviate from unity as predicted by equations (4) and (5). This effect is not significant and can be easily compensated, if required, by an additional current amplifier or attenuator.

\subsubsection{Lossless Integrators}

In a similar way the effect of transistors mismatch on the performance of the lossless integrator of Fig. 5 can be studied. Using the small signal model of the MOS transistor of Fig. 17, ignoring the effects of $C_{g s}$ and $g_{d s}$ and assuming that the transconductances of the MOS transistors are $g_{m 1}$ for the transistor $\mathrm{M}_{1}$ and $g_{m 2}$ for the transistors $\mathrm{M}_{2}$ and $M_{3}$ respectively, reanalysis shows that the transfer function of the lossless integrator of Fig. 5 can be expressed by (44) 


$$
\frac{I_{O A}}{I_{I N}}=\frac{-I_{O B}}{I_{I N}}=\frac{-g_{m 2}}{g_{m 1}-g_{m 2}+s C_{1}}
$$

Inspection of equation (44) shows that, due to the transistor mismatch, the lossless integrator becomes a lossy integrator with a very low frequency pole at

$$
\omega_{p}=\frac{g_{m 1}-g_{m 2}}{C_{1}} .
$$

This low-frequency pole will be at zero frequency when $g_{m 1}=g_{m 2}$ resulting in an ideal lossless integrator. But it may be moved slightly in the right-half plane if $g_{m 1}>g_{m 2}$ or slightly in the left-half plane if $g_{m 1}<g_{m 2}$. Thus, in order to avoid any unexpected performance care must be taken to ensure that $g_{m 1} \geq g_{m 2}$. This can be easily achieved by trimming the bias currents of the transistors.

\section{Simulation Results}

This section describes the simulation results of the proposed electronically tunable current-mode ladder thirdorder low-pass filters. PSPICE simulation results are carried out by using TSMC $0.18 \mu \mathrm{m}$ CMOS technology, $+1.5 \mathrm{~V}$ power supply. The extracted small signal parameters of NMOS and PMOS are $\lambda_{n}=0.1 \mathrm{~V}^{-1}, \mu_{n} C_{o x}=$ $100 \mu \mathrm{A} / \mathrm{V}^{2}, \quad V_{T H n}=0.37 \mathrm{~V}$ and $\lambda_{p}=0.1 \mathrm{~V}^{-1}, \quad \mu_{p} C_{o x}=$ $25 \mu \mathrm{A} / \mathrm{V}^{2}, V_{T H p}=0.38 \mathrm{~V}$ respectively. The minimization of the aspect ratio $W / L$ is required for obtaining the desired transconductance with minimum error and die area. Thus, the aspect ratios of the transistors used in Figs. 13 and 15 were selected as $W / L=70 \mu \mathrm{m} / 0.36 \mu \mathrm{m}$. The bias currents $I_{B}$ are provided by using positive current mirrors (PMOS) with identical aspect ratio $W / L=100 \mu \mathrm{m} / 0.36 \mu \mathrm{m}$. The special NMOS transistors $\left(M_{19}\right.$ and $\left.M_{24}\right)$ of Fig. 15 use $W / L=4.8 \mu \mathrm{m} / 0.36 \mu \mathrm{m}$ for obtaining the current gain $k=0.07$. The special PMOS transistors $\left(M_{B 20}\right.$ and $\left.M_{B 25}\right)$ of Fig. 15 use of $W / L=6.8 \mu \mathrm{m} / 0.36 \mu \mathrm{m}$ to achieve the bias current $0.07 I_{B}$.

The simulated DC transfer characteristic of the proposed lossy integrator is shown in Fig. 18. Inspection of Fig. 18 clearly shows that large values of channel length $L$ result in smaller error and DC-offset than the small values of $L$. However, it is a trade-off between the error and die area minimizations. Using more accurate current mirror structures; for example cascode current mirrors and large values of $L$ would result in smaller errors but a large die area, complex structures and more power consumption will be the price for this reduced error.

In order to verify the operation of the transistors in the saturation region, the values of $V_{G S}$ and $V_{D S}$ were monitored over the bias current range $[0.03,0.3,3,30,300] \mu \mathrm{A}$ for the transistors $M_{1}$ and $M_{2}$ of the lossy integrator of Fig. 2 and transistors $M_{1}-M_{5}$ of the lossless integrator of Fig. 5. In all cases it was found that $V_{D S}>V_{G S}-V_{T H N}$ and $V_{G S}>V_{T H N}$. Thus, the operation of the transistors in the saturation region is confirmed for the bias current range of interest.

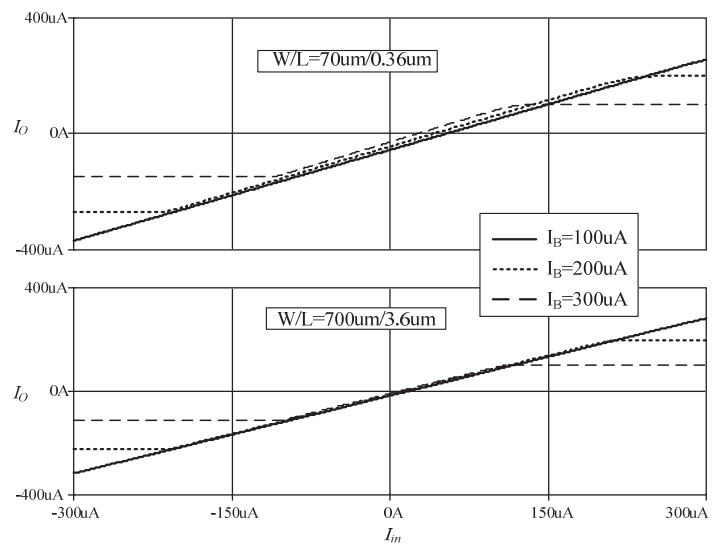

Fig. 18. DC-characteristic of the proposed lossy integrator using different values of $W / L$.

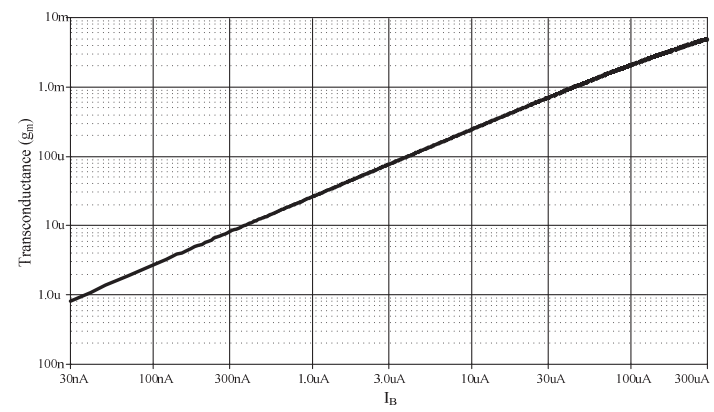

Fig. 19. Transconductance of a MOS transistor against its bias current.

Variations of the transconductance of the MOS transistor were also measured as a function of the bias current of the transistor aspect ratio $W / L=70 \mu \mathrm{m} / 0.36 \mu \mathrm{m}$. The result shown in Fig. 19 confirms the dependence of the transconductance on the bias current.

The frequency response of CMOS lossy integrator of Fig. 2 and CMOS lossless integrator of Fig. 5 are depicted in Fig. 20 and 21, respectively. As explained in Sec. 4.1, the capacitor $C_{1}=10 \mathrm{pF}$ is selected for minimizing the effect of parasitic capacitances and the bias current $I_{B}$ was varied in the range $[0.03,0.3,3,30,300] \mu \mathrm{A}$. Figures 20 and 21 clearly show that the frequency response can be tuned, using the bias current, over a wide range of frequencies $(10 \mathrm{kHz}$ to $100 \mathrm{MHz})$. From Fig. 21, the low-frequency current gain of the lossless integrator is around $25 \mathrm{~dB}$. This agrees well with the theory presented in Sec. 4.2.2. Inspection of Fig. 21 clearly shows that there is a parasitic zero in the gain-frequency characteristic. This parasitic zero can be attributed to the parasitic output resistances of the MOSFETs which is inversely proportional to the transistor length $L$. Thus, for $L=0.36 \mu \mathrm{m}$ and bias current $I_{B}=300 \mu \mathrm{A}$ the output resistance of the transistor will be approximately $33 \mathrm{k} \Omega$. This is a relatively low value and would result, in conjunction with the transistor parasitic capacitance, in a parasitic zero in the transfer characteristic. However, as shown in Fig. 21, this parasitic zero manifests itself at relatively high frequencies outside the frequency ranges of interest. 

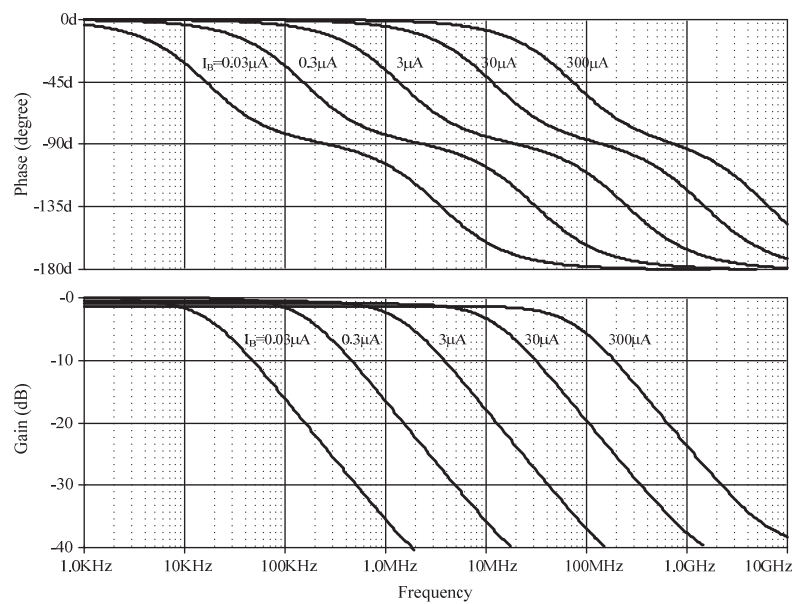

Fig. 20. Magnitude and phase responses of CMOS lossy integrator of Fig. 2 by varying bias current $I_{B}$
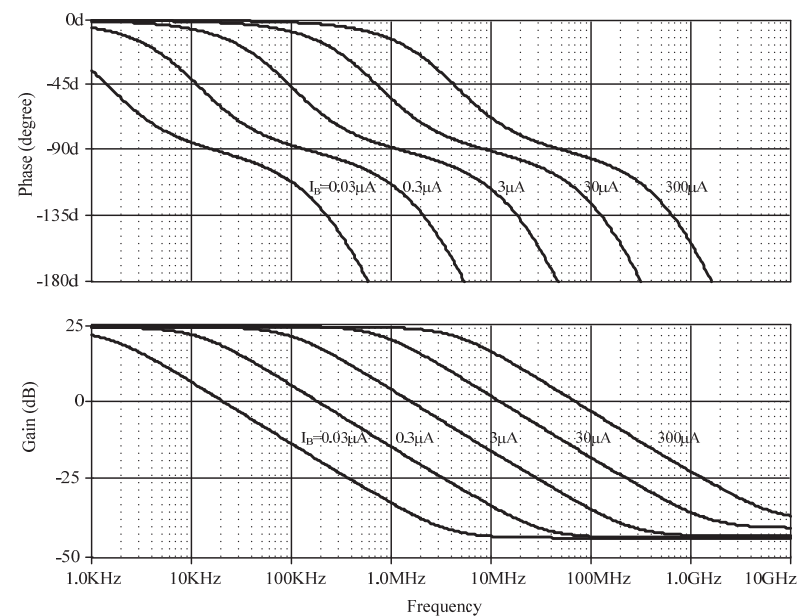

Fig. 21. Magnitude and phase responses of CMOS lossless integrator in Fig. 5 by varying bias current $I_{B}$.

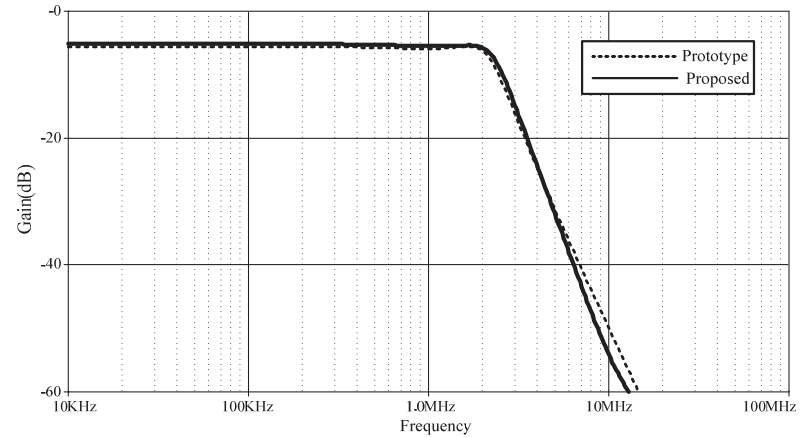

Fig. 22. Comparison of proposed all-pole LPF with RLC prototype $\left(I_{B}=2.7 \mu \mathrm{A}\right)$.

The specifications of the prototype third-order filter with Chebyshev response are as follows: Cut-off frequency $=2 \mathrm{MHz}, A_{\max }=-6 \mathrm{~dB}$ and passband ripple $=0.1 \mathrm{~dB}$ [27]. The RLC prototype of Fig. 7 was simulated using the following components, $C_{1}=C_{3}=128 \mathrm{nF}, L_{2}=88 \mathrm{nH}, R_{S}=R_{L}$ $=1 \Omega$ and the proposed all-pole filter of Fig. 13 was simulated using the following components, the capacitors $C_{1}=$ $C_{3}=12 \mathrm{pF} \quad(W / L=40 \mu \mathrm{m} / 40 \mu \mathrm{m}), \quad C_{2}=8 \mathrm{pF} \quad(W / L=$ $32 \mu \mathrm{m} / 32 \mu \mathrm{m})$ and bias current $I_{B}=2.7 \mu \mathrm{A}$. The simula-

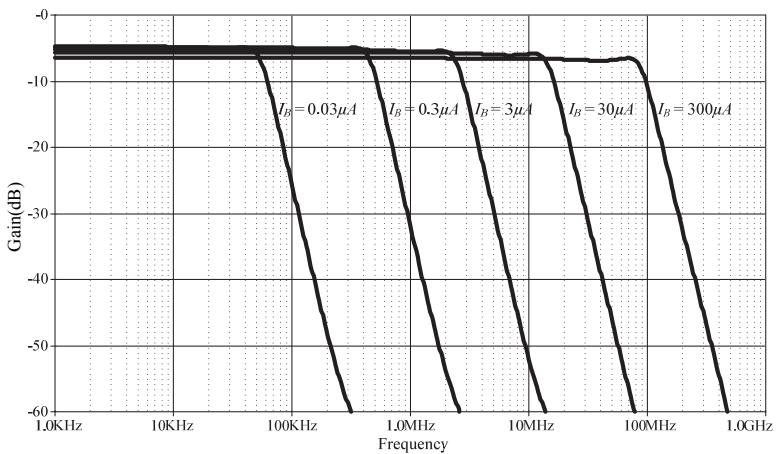

Fig. 23. Magnitude response of proposed third-order all-pole LPF as a function of the bias current $I_{B}$.

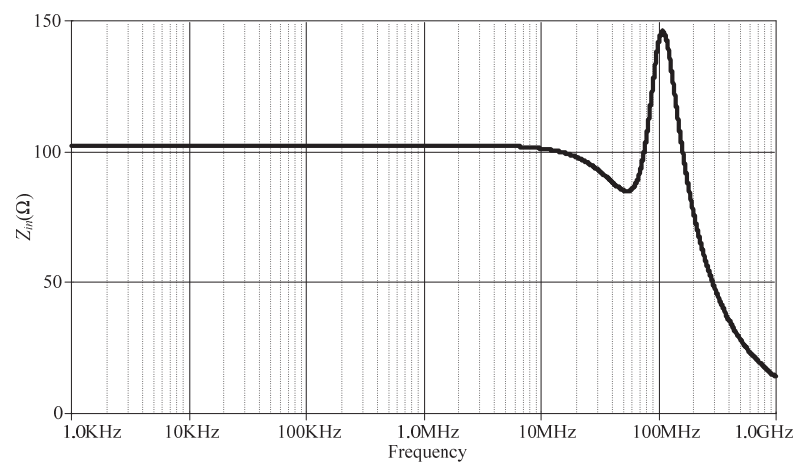

Fig. 24. Input impedance of the proposed all-pole low-pass filter at bias current $I_{B}=300 \mu \mathrm{A}$.

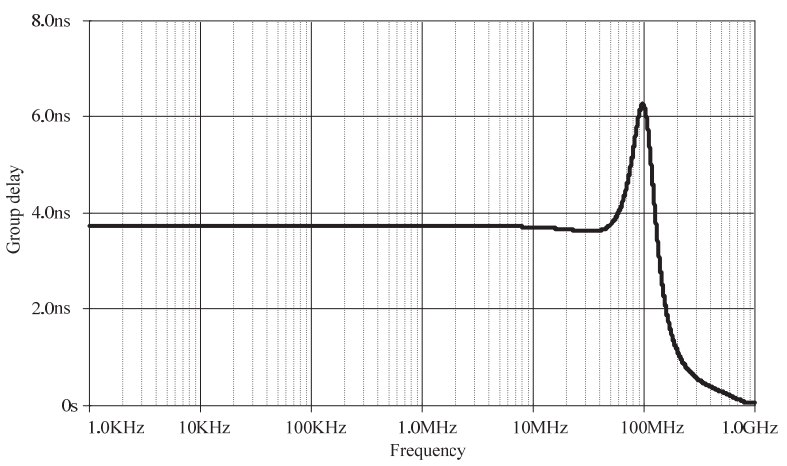

Fig. 25. Group delay of the proposed all-pole low-pass filter at bias current $I_{B}=300 \mu \mathrm{A}$.

tion results obtained from the RLC prototype filter of Fig. 7 and the proposed all-pole filter in Fig. 13 is shown in Fig. 22. It can be seen that the frequency response of the proposed filter and the RLC prototype are very close but the slope of the stop band has slight deviations. The electronically-tuned feature of the proposed third-order all-pole low-pass filter can be provided by adjusting the bias current $I_{B}[0.03,0.3,3,30,300] \mu \mathrm{A}$. The frequency response of the filter can be tuned over a wide range of frequencies $(10 \mathrm{kHz}$ and $100 \mathrm{MHz})$ as shown in Fig. 23. It can be seen that the results are in agreement with the theoretical predictions.

Figure 24 shows that the variation of the input impedance at a bias current $I_{B}=300 \mu \mathrm{A}$. Inspection of Fig. 24 shows that the input impedance is around $100 \Omega$ along the pass-band frequency of around $100 \mathrm{MHz}$ and becomes 
almost zero within the stop-band. Thus, the input impedance is relatively low over a wide range of the pass band. Figure 25 shows the group delay of the proposed all-pole low-pass filter. It can be seen that the group delay is flat along the pass-band with a value around $4 \mathrm{~ns}$.

The specifications of the prototype third-order Elliptic filter are as follows: the cut-off frequency $=2 \mathrm{MHz}, A_{\max }=$ $-6 \mathrm{~dB}, A_{\min }=-35 \mathrm{~dB}$, and passband ripple $=0.1 \mathrm{~dB}$ [27]. The Elliptic prototype low-pass filter of Fig. 9 was simulated using the following components: $C_{1}=C_{4}=$ $120 \mathrm{nF}, C_{3}=11.4 \mathrm{nF}, L_{2}=102.8 \mathrm{nH}$ and $R_{S}=R_{L}=1 \Omega$. The proposed Elliptic filter of Fig. 15 was simulated using the following components: $C_{A}=C_{B}=\left(C_{1}+C_{3}\right)=\left(C_{3}+C_{4}\right)$ $=8.5 \mathrm{pF}(W / L=50 \mu \mathrm{m} / 50 \mu \mathrm{m})$ and $C_{2}=7.5 \mathrm{pF} \quad(W / L$ $=45 \mu \mathrm{m} / 45 \mu \mathrm{m})$ and bias current $I_{B}=5 \mu \mathrm{A}$. The simulation results obtained from the proposed Elliptic LPF and the RLC prototype are depicted in Fig. 26. It can be seen that the magnitude response of the proposed Elliptic filter is quite similar to that of the prototype Elliptic filter but the stop-band magnitude is slightly different.

The electronically-tuned feature of the proposed thirdorder Elliptic low-pass filter can be provided by adjusting the bias current $I_{B}[0.03,0.3,3,30,300] \mu \mathrm{A}$. The frequency response of the filter can be tuned over a wide frequency range as shown in Fig. 27. It can be seen that the results are in good agreement with the theoretical predictions.

Figure 28 shows the variation of the input impedance of the Elliptic low-pass filter. The input impedance with bias current $I_{B}=300 \mu \mathrm{A}$ is obtained around $100 \Omega$ along

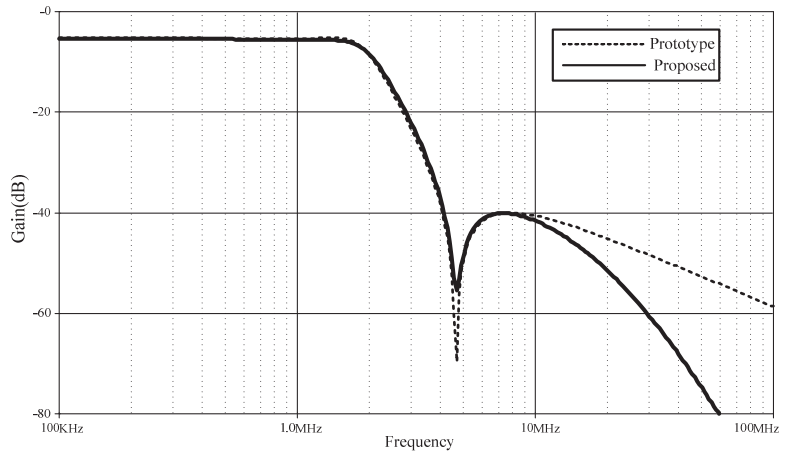

Fig. 26. Comparison of the proposed Elliptic LPF with the RLC prototype.

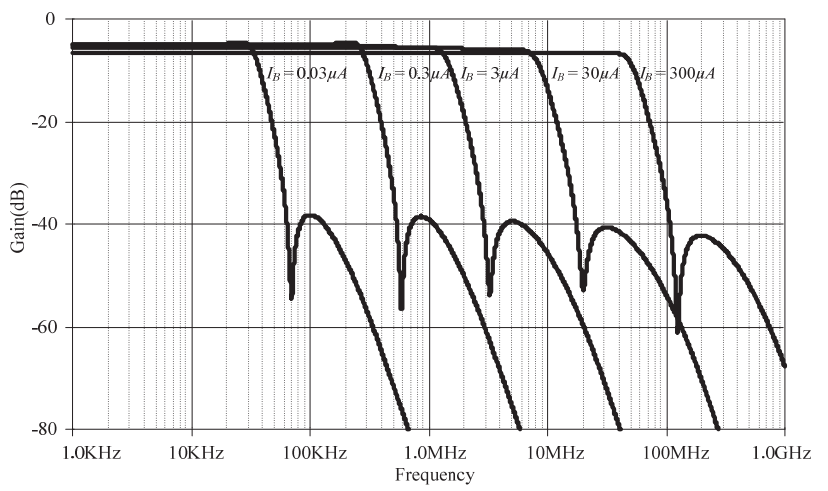

Fig. 27. Magnitude response of the proposed third-order Elliptic LPF as a function of the bias current $I_{B}$.

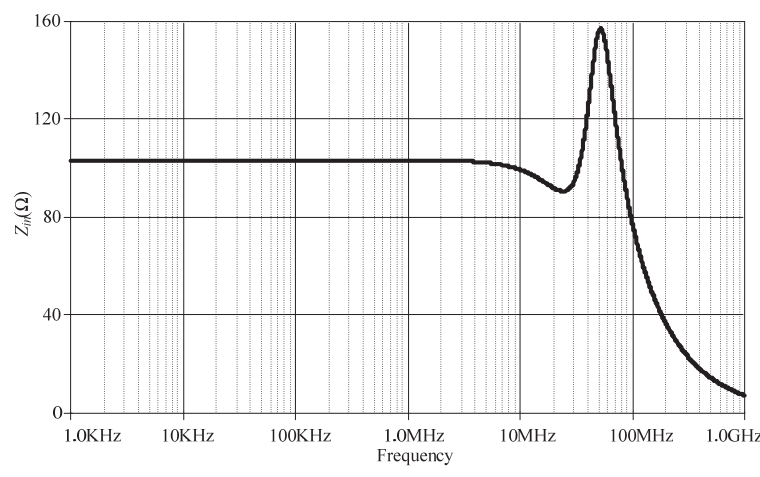

Fig. 28. Input impedance of the proposed Elliptic low-pass filter at bias current $I_{B}=300 \mu \mathrm{A}$.

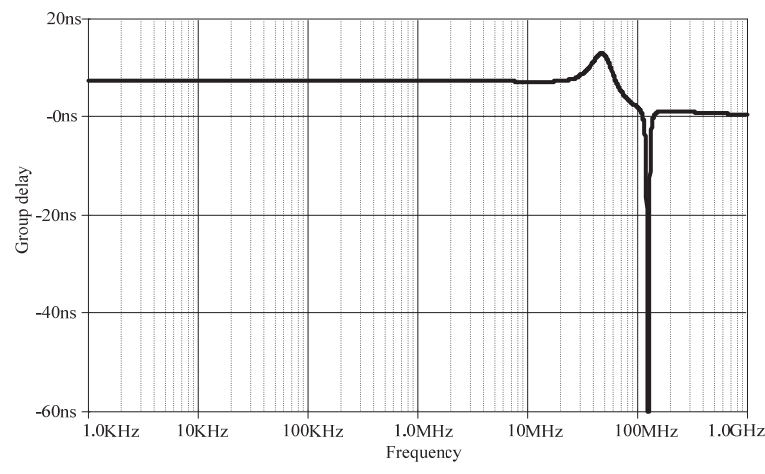

Fig. 29. Group delay of the proposed Elliptic low-pass filter at bias current $I_{B}=300 \mu \mathrm{A}$.

the pass-band frequency of around $100 \mathrm{MHz}$ and becomes almost zero in the stop-band. Thus, the input impedance is relatively low over a wide range of the pass band. Fig. 29 shows the group delay of the proposed Elliptic low-pass filter at bias current $I_{B}=300 \mu \mathrm{A}$. It can be seen that the group delay is flat along the pass-band with a value around 4 ns.

The performance of the proposed third-order all-pole and Elliptic low-pass filters can also be verified by applying multi tones $(10,40,70,100,130,160,190$ and $220 \mathrm{MHz}$ ) to the filters at the bias current equal to $300 \mu \mathrm{A}$. From Figs. 30 and 31, it appears that the out-of-band tones $(>100 \mathrm{MHz}$ ) have been removed and only the in-band tones $(<100 \mathrm{MHz})$ can be obtained at the output. Furthermore, it can be seen that, with the same order of the filter, the characteristic of the Elliptic filter is better than that of the all-pole counterpart especially in removing signals in the stop-band.

The total harmonic distortion (THD) of the proposed third-order all-pole and Elliptic low-pass filters was measured and the results are shown in Fig. 32 and 33, respectively. The results were obtained by applying two sinusoids with variable amplitudes at two frequencies (1 MHz and $10 \mathrm{MHz}$ ) with bias current $I_{B}=300 \mu \mathrm{A}$. The THD at $10 \mathrm{MHz}$ of the proposed filters are found to be below $0.7 \%$ and $0.6 \%$, respectively.

The performance of the proposed filters can be verified by applying the in-band signal into the filters. Both of the filters are setting the frequency cut-off at $100 \mathrm{MHz}$ based on $300 \mu \mathrm{A}$ of the bias current. Sinusoidal signals of 

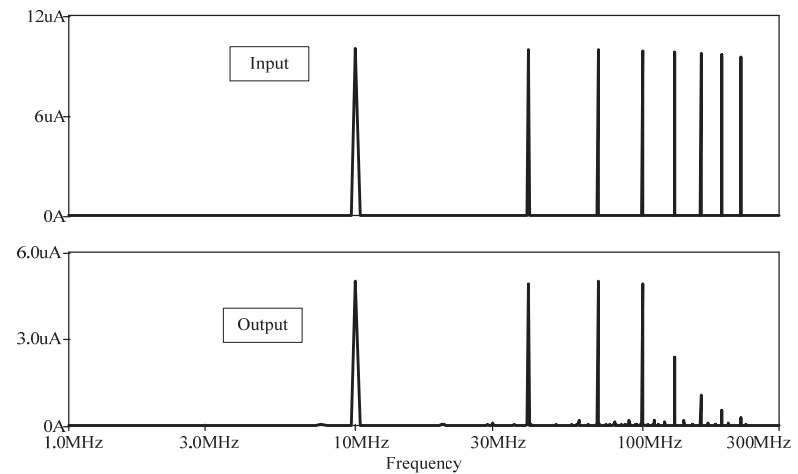

Fig. 30. Multi tones measurement of the proposed third-order all-pole low-pass filter at bias current $I_{B}=300 \mu \mathrm{A}$.
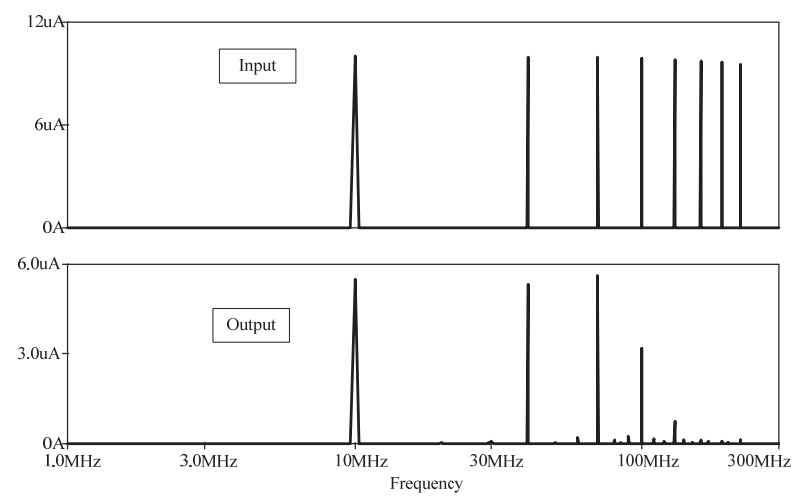

Fig. 31. Multi tones measurement of the proposed third-order Elliptic low-pass filter at bias current $I_{B}=300 \mu \mathrm{A}$.

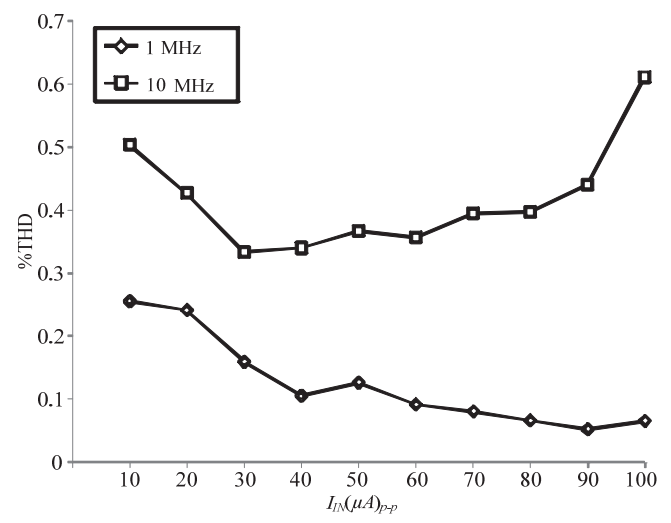

Fig. 32. THD of the proposed third-order all-pole low-pass filter at bias current $I_{B}=300 \mu \mathrm{A}$.

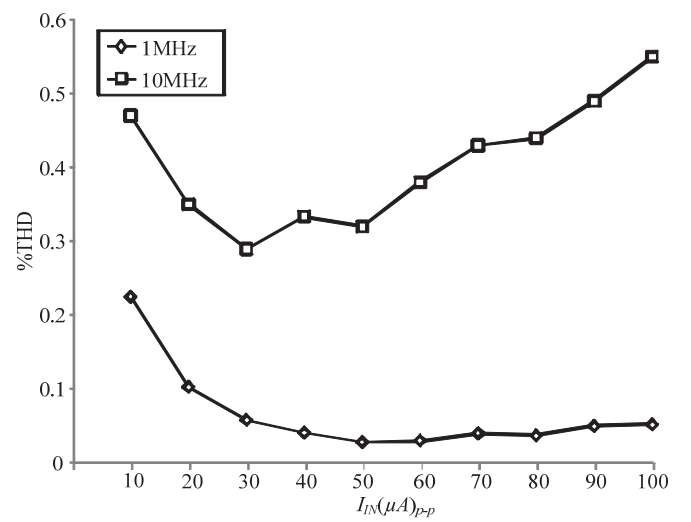

Fig. 33. THD of the proposed third-order Elliptic low-pass filter at bias current $I_{B}=300 \mu \mathrm{A}$.

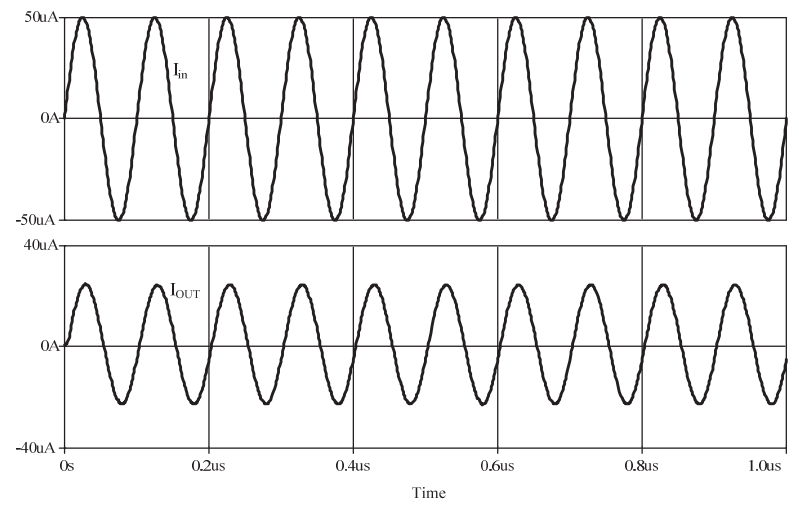

Fig. 34. Input and output of $10 \mathrm{MHz}$ waveforms of Chebyshev $\mathrm{LPF}$ at bias current $I_{B}=300 \mu \mathrm{A}$.

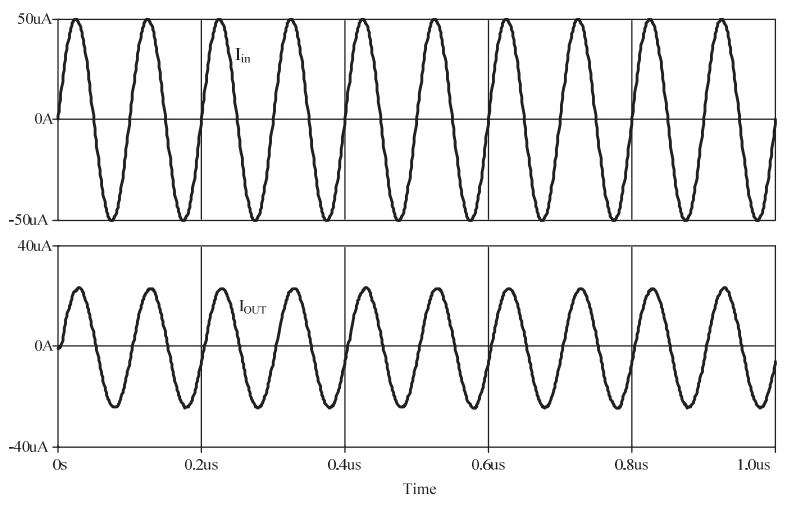

Fig. 35. Input and output of $10 \mathrm{MHz}$ waveforms of the Elliptic LPF at bias current $I_{B}=300 \mu \mathrm{A}$.

$10 \mathrm{MHz}$ with $30 \mu \mathrm{A}_{\mathrm{p}-\mathrm{p}}$ are applied to the both filters. It can be seen that the sinusoidal signal can be obtained at the outputs of the proposed Chebyshev and Elliptic filters as shown in Fig. 34 and 35, respectively. It is evidently found that in-band signal can be passed the proposed filters with low distortion.

Transistor mismatches are the major sources of errors in the proposed MOSFET based filters. To investigate the effect of transistor mismatches on the performance of the proposed filters Monte Carlo analysis was performed. A hundred of samples are run for verifying the frequency response. The $2 \%$ uniform deviation of NMOS transistors surface mobility $\mu$ with bias current $I_{B}=300 \mu \mathrm{A}$ is assumed. The results are shown in Figs. 36 and 37. Inspection of Fig. 36 shows that the cutoff frequency of the filter deviates from its nominal value by about $\pm 2 \mathrm{MHz}$ which corresponds to $\pm 2 \%$.

Inspection of Fig. 37 shows that the cut-off frequency of the Elliptic filter deviates from its nominal value by about $\pm 2 \mathrm{MHz}$ which corresponds to $\pm 2 \%$ error. In order to investigate the feasibility of integrated circuit fabrication and to estimate the area on the chip of the proposed circuits, the physical layout of the proposed low-pass Chebyshev and Elliptic filters were obtained and are shown in Figs. 38 and 39 respectively. The resulting dimensions of these layouts are approximately $200 \mu \mathrm{m} \times 240 \mu \mathrm{m}$ and $210 \mu \mathrm{m} \times 360 \mu \mathrm{m}$, for Chebyshev and Elliptic filters, respectively. 


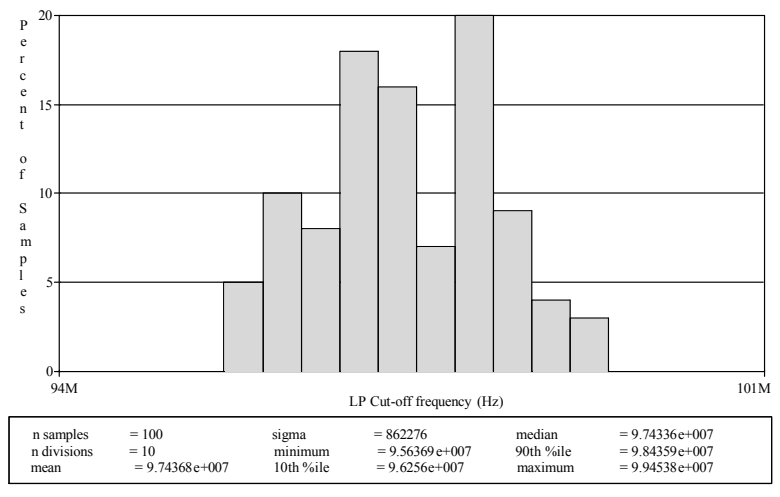

Fig. 36. Monte Carlo analysis of the cut-off frequency of the all-pole low-pass filter based on $2 \%$ surface mobility deviations the of NMOS transistors $\left(M_{1}-M_{15}\right)$ with $I_{B}=$ $300 \mu \mathrm{A}$.

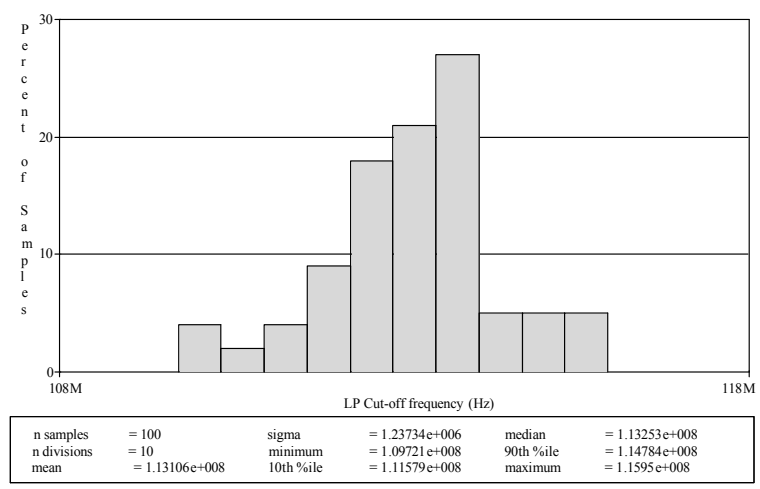

Fig. 37. Monte Carlo analysis of the cut-off frequency of the Elliptic low-pass filter based on $2 \%$ surface mobility deviations of the NMOS transistors $\left(M_{1}-M_{25}\right)$ with $I_{B}=$ $300 \mu \mathrm{A}$.

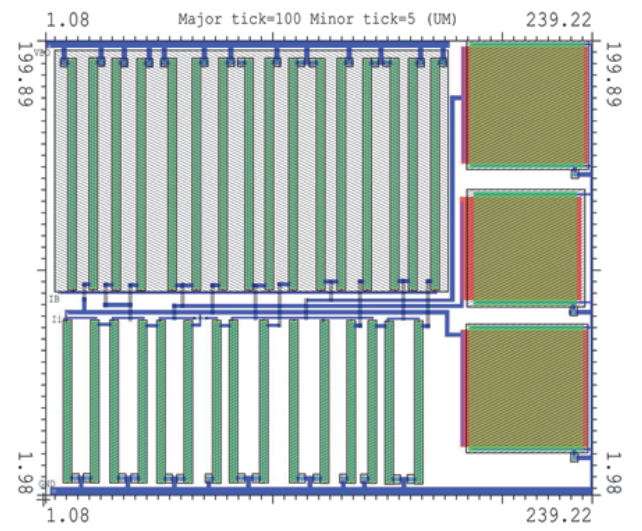

Fig. 38. The physical layout of the low-pass Chebyshev filter.

Table 1 shows a comparison of the performance of the proposed all-pole and Elliptic third-order ladder low-pass filters with previously published filters. Most of the previous works cannot be operated at relatively very high frequencies and have no electronic tunability feature because of the limitation of the used active devices. Most of the pervious works use excessive number of transistors and relatively large power supply voltages. It can be seen that the proposed filters use a low number of components without any externally connected resistors compared with previously published works. Table 1 shows that electronic

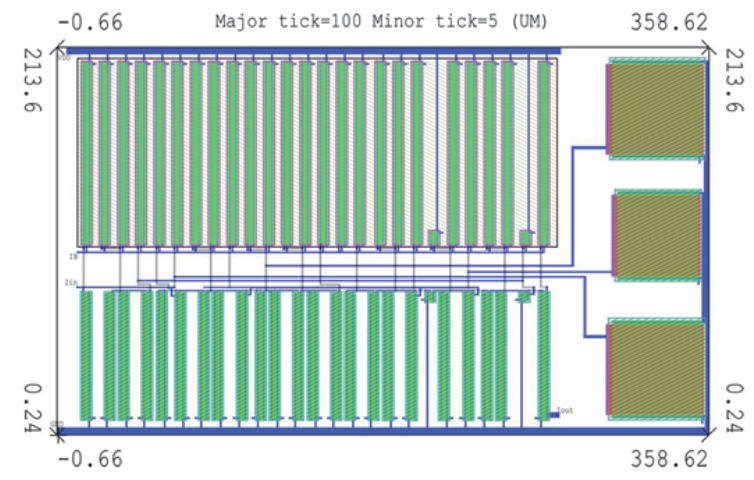

Fig. 39. The physical layout of the Elliptic low-pass filter.

\begin{tabular}{|c|c|c|c|c|c|c|c|}
\hline Filters & $\begin{array}{c}\text { Power } \\
\text { supply }\end{array}$ & $\begin{array}{c}\text { Frequency } \\
\text { range }\end{array}$ & $\begin{array}{c}\text { Number of } \\
\text { transistors }\end{array}$ & $\begin{array}{c}\text { Use of } \\
\text { resistors }\end{array}$ & $\begin{array}{c}\text { Electronic } \\
\text { Tunability }\end{array}$ & $\begin{array}{c}\text { Power } \\
\text { Dissipation } \\
\boldsymbol{I}_{\boldsymbol{B}}=\mathbf{1 0 0 \mu \mathrm { A } )}\end{array}$ & THD \\
\hline$[7]$ & $+1.5 \mathrm{~V}$ & $>10 \mathrm{MHz}$ & 146 & No & Yes & $6.2 \mathrm{~mW}$ & $<1 \%$ \\
\hline$[8]$ & $\pm 2 \mathrm{~V}$ & $<100 \mathrm{MHz}$ & 154 & No & Yes & NA & NA \\
\hline$[9]$ & $\pm 5 \mathrm{~V}$ & $<10 \mathrm{MHz}$ & 104 & No & No & $14 \mathrm{~mW}$ & $<1 \%$ \\
\hline$[10]$ & $\pm 5 \mathrm{~V}$ & $<100 \mathrm{MHz}$ & 72 & No & No & NA & NA \\
\hline$[11]$ & $\pm 3 \mathrm{~V}$ & $<10 \mathrm{MHz}$ & 123 & No & No & NA & NA \\
\hline$[12]$ & $\pm 1 \mathrm{~V}$ & $<10 \mathrm{MHz}$ & 123 & No & No & NA & NA \\
\hline$[13]$ & $\pm 1 \mathrm{~V}$ & $<10 \mathrm{MHz}$ & 85 & Yes & No & NA & NA \\
\hline$[14]$ & $\pm 2.5 \mathrm{~V}$ & $<10 \mathrm{MHz}$ & 90 & Yes & No & NA & NA \\
\hline$[15]$ & $\pm 1.8 \mathrm{~V}$ & $<10 \mathrm{MHz}$ & 171 & No & No & NA & NA \\
\hline$[16]$ & $\pm 2.5 \mathrm{~V}$ & $<10 \mathrm{MHz}$ & 84 & Yes & No & NA & NA \\
\hline Proposed1 & $+1.5 \mathrm{~V}$ & $<100 \mathrm{MHz}$ & 31 & No & Yes & $3 \mathrm{~mW}$ & $<1 \%$ \\
\hline Proposed2 & $+1.5 \mathrm{~V}$ & $<100 \mathrm{MHz}$ & 53 & No & Yes & $5 \mathrm{~mW}$ & $<1 \%$ \\
\hline
\end{tabular}

Tab. 1. Comparison of previous works with the proposed filters.

tunability, low power dissipation (at same bias current) and operation at relatively very high frequencies are the most outstanding features of the proposed filters.

\section{Conclusion}

CMOS third-order current-mode all-pole and Elliptic low-pass filters based on RLC ladder prototype have been proposed. The filters are built around lossy and lossless integrators, current splitters and grounded capacitors. They enjoy wide tuning range of the frequency responses in the range $10 \mathrm{kHz}$ and $100 \mathrm{MHz}$ by using bias current from $0.03 \mu \mathrm{A}$ to $300 \mu \mathrm{A}$. The circuits use only single $+1.5 \mathrm{~V} \mathrm{DC}$ power supply with dynamic power consumption around $8.9 \mathrm{~mW}$ and $16.9 \mathrm{~mW}(300 \mu \mathrm{A}$ bias current $)$ and occupied $200 \mu \mathrm{m} \times 240 \mu \mathrm{m}$ and $210 \mu \mathrm{m} \times 360 \mu \mathrm{m}$, for Chebyshev and Elliptic filters, respectively. The proposed circuits enjoy low complexity structures, with low number of components, low-voltage, low THD, relatively low input impedance and high-frequency operation. All the proposed filters are suitable for integration and can be used for high frequencies up to the VHF range.

\section{References}

[1] RAUT, R., SWAMY, M. N. S. Modern Analog Filter Analysis and Design. Weinheim (Germany): Wiley-VCH Verlag GmbH \& Co. KGaA, 2010. ISBN: 9783527407668

[2] RAUT, R., GUO, N. Low power wideband voltage and current mode second-order filters using wideband CMOS transimpedance network. In Proceedings of the 40th Midwest Symposium on 
Circuits and Systems MWSCAS. Aug. 1997, vol. 1, p. 241-244. DOI: 10.1109/MWSCAS.1997.666078

[3] FABRE, A., DAYOUB, F., DURUISSEAU, L., KAMOUN, M. High input impedance insensitive second-order filters implemented from current conveyors. IEEE Transactions on Circuits and Systems I: Fundamental Theory and Applications, Dec. 1994, vol. 41, no.12, p. 918-921. DOI: 10.1109/81.340859

[4] LUCK, J., SWANSON, J. G. First-order, switched-capacitor, lowpass filter implemented with GaAs insulated-gate FET switches. Electronics Letters, Oct. 1990, vol. 26, no. 22, p. 1843-1845. DOI:10.1049/el:19901186

[5] BANERJEe, K., RANJAN, A., PAUL, S. K. New first order multifunction filter employing operational transresistance amplifier. In Proceedings of 5th International Conference on Computers and Devices for Communication (CODEC 2012). Dec. 2012, p. 1-3. DOI: 10.1109/CODEC.2012.6509218

[6] CHEN, W. K. The Circuits and Filters Handbook. A CRC Handbook Published in Cooperation with IEEE Press, 1995. ISBN: 9781420055276

[7] SA-AD, S., CHAYTHONG, D. A high frequency current-mode ladder filter using multiple output lossless integrator. In Proceedings of International Symposium on Intelligent Signal Processing and Communications Systems, ISPACS 2008. Feb. 2009, p. 1-4. DOI:10.1109/ISPACS.2009.4806743

[8] JIRASEREE-AMORNKUN, A., FUJII, N., SURAKAMPONTORN, W., Realization of electronically tunable ladder filters using multi-output current controlled conveyors. In Proceedings of the International Symposium on Circuits and Systems 2003, ISCAS'03. May 2003, vol. 1, p. 541-544. DOI:10.1109/ ISCAS.2003.1205620

[9] ZELE, R. H., ALLSTOT, D. J., FIEZ, T. S. Fully balanced CMOS current-mode circuits. IEEE Journal of Solid-State Circuits, 1993 , vol. 28 , no. 5, p. 569-575. DOI: $10.1109 / 4.229398$

[10] ORALKAN, O., KARSILAYAN, A. I., TAN, M. A. Design of allpole low-pass ladder filters using current-mode damped integrators. In Proceedings of the International Symposium on Circuits and Systems, ISCAS'96. May 1996, vol. 1, p. 266-269. DOI: 10.1109/ISCAS.1996.539880

[11] WU, J., EL-MASRY, E. A new approach of design of currentmode filters. In Proceedings of International Symposium on Circuits and Systems, ISCAS'97. Jun. 1997, vol. 1, p. 317-320. DOI: 10.1109/ISCAS.1997.608721

[12] WU, J., EL-MASRY, E. Design of current-mode ladder filters using coupled-biquads. IEEE Transactions on Circuits and Systems II: Analog and Digital Signal Processing, Nov. 1998, vol. 45 , no. 11 , p. $1445-1454$. DOI: $10.1109 / 82.735356$

[13] TANGSRIRAT, W., FUJII, N., SURAKAMPONTORN W. Current-mode leapfrog ladder filters using CDBAs. In Proceedings of International Symposium on Circuits and Systems, ISCAS 2002. 2002, vol. 5, p. 57-60. DOI: 10.1109/ISCAS. 2002.1010639

[14] YAN-HUI, X., XUE, L. Active simulation of passive leapfrog ladder filters using DVCCs. In Proceedings of International Conference on Industrial Technology, ICIT 2008. Apr. 2008, p. 1-5. DOI:10.1109/ICIT.2008.4608606

[15] YAN-HUI, X., PENG, H. Realization of low-pass and band-pass leapfrog filters using OAs and CCCIIs. In Proceedings of International Conference Management and Service Science, MASS'09. Sep. 2009, p. 1-4. DOI: 10.1109/ICMSS.2009.5303743

[16] WU, J., EL-MASRY, E. Current-mode ladder filters using multiple output current conveyors. IEE Circuits, Devices and Systems, 1996, vol. 143, no. 4, p. 218-222. DOI: 10.1049/ipcds: 19960490

[17] YUCE, E., MINAEI, S. On the realization of high-order currentmode filter employing current controlled conveyors. Computers and Electrical Engineering, May 2008, vol. 34, no. 3, p. 165-172. DOI:10.1016/j.compeleceng.2007.04.001

[18] YUCE, E., MINAEI, S. ICCII-based universal current-mode analog filter employing only grounded passive components. Analog Integrated Circuits and Signal Processing, Feb. 2009, vol. 58, no. 2, p. 161-169. DOI: 10.1007/s10470-008-9225-2

[19] SINHA, P. K., SAINI, A., KUMAR, P., MISHRA, S., CFOA based low pass and high pass ladder filter-a new configuration Circuits and Systems, 2014, vol. 5, no. 12, p. 293-300. DOI: $10.4236 /$ cs.2014.512030

[20] PROMMEE, P., WONGPROMMOON, N. Tunable CMOS-based current mode fifth-order ladder low-pass filter. In Proceedings of the 36th International Conference on Telecommunications and Signal Processing (TSP). Jul. 2013, p. 397-401. DOI: 10.1109 /TSP.2013.6613961

[21] ANANDA MOHAN, P. V. Current-Mode VLSI Analog Filters: Design and Applications. Birkhauser Boston, 2003. ISBN: 9781461200338

[22] DELIYANNIS, T., SUN, Y., FIDLER, J. K. Continuous-Time Active Filter Design. London (UK): CRC Press, 1999. ISBN: 9780849325731

[23] SCHAUMANN, R., GHAUSI, M. S., LAKER, K. R. Design of Analog Filters: Passive, Active RC and Switched Capacitor. Prentice Hall, 1995. ISBN: 9780132002882

[24] ALLSTOT, D. J., BRODERSEN, R. W., GRAY, P. R. Fullyintegrated high-order NMOS sampled-data ladder filters. In Proceedings of IEEE Intl. Solid-State Circuits Conf. New York, 1978, vol. 21, p. 82-83. DOI. 10.1109/ISSCC.1978.1155789

[25] PENNEY, W. M., LAU, L. MOS Integrated Circuits, Theory, Fabrication, Design, and Systems Applications of MOS LSI. American Micro-Systems Inc., 1972. ISBN: 9780442203528

[26] BAKER, R. J. CMOS Circuit Design, Layout, and Simulation. Wiley - Interscience. 2008. ISBN: 9780470881323

[27] HUElSMAN, L. P. Active and Passive Analog Filter Design. McGraw-Hill Inc., International Edition, 1993. ISBN: 9780070308602

\section{About the Authors...}

Terdsak KUNTO received B. Ind. Tech. degree in Telecommunications from the Faculty of Engineering, King Mongkut's University of Technology North Bangkok (KMUTNB), Bangkok, Thailand in 2009, and M.Eng. degree in Telecommunications Engineering from the Faculty of Engineering, King Mongkut's Inst. of Technology Ladkrabang (KMITL), Bangkok, Thailand in 2013. He is now pursuing a doctoral degree in Electrical Engineering, KMITL.

Pipat PROMMEE received his B. Ind. Tech. degree in Telecommunications, M.Eng. and D.Eng. in Electrical Engineering from the Faculty of Engineering, King Mongkut's Inst. of Technology Ladkrabang (KMITL), Bangkok, Thailand in 1992, 1995 and 2002, respectively. $\mathrm{He}$ was a senior engineer of CAT telecom plc. between 1992 and 2003. Since 2003, he has been a faculty member of KMITL. He is currently an associate professor at the Telecommunications Engineering Dept. at KMITL. He is author or co-author of more than 60 publications in journals and proceedings of international conferences. His research interests are focusing in analog signal processing, 
analog filter design and CMOS analog integrated circuit design. He is a member of IEEE, USA.

Muhammad Taher ABUELMA'ATTI was born in Cairo, Egypt, in 1942. He received the B.Sc. degree in Electrical Engineering from the University of Cairo, Cairo, Egypt, in 1963, and the Ph.D. degree and the Doctor of Science degree, both from the University of Bradford, Bradford, England, in 1979 and 1999, respectively. From 1963 to 1967, he was at the Military Technical College, Cairo, as a Teaching Assistant. He was with the Iron and Steel Company in Helwan, Cairo, from 1967 to 1973 as a Senior Electrical Engineer. From 1973 to 1976, he was with the College of Engineering, University of Riyadh, Riyadh, Saudi Arabia, as a Teaching Assistant. From 1980 to 1981, he was with the Faculty of Engineering, University of Khartoum, Khartoum, Sudan, as an Assistant Professor, and from 1981 to 1982 he was with the College of Engi- neering, King Saud University, Riyadh, Saudi Arabia, as an Assistant Professor. In 1982, he joined the College of Engineering, University of Bahrain and in 1987 he became an Associate Professor. In 1991 he joined the College of Engineering Sciences, King Fahd University of Petroleum and Minerals, Dhahran, Saudi Arabia, where he became a Full Professor in January 1995 and in April 2008 he became a Distinguished University Professor. In April 2009, he was appointed as an Honorary Visiting Professor at the Department of Electronic and Electrical Engineering, University of Manchester, Manchester, U.K. He is the author or coauthor of more than 600 journal articles and technical presentations. According to Scopus (Elsevier) his current "h-index" is 23. His research interests include problems related to analysis and design of nonlinear electronic circuits and systems, analog integrated circuits, and active networks design. 